\title{
Effects of Air Conditioner Operating Environments on the Fatigue of Heat Exchanger Aluminum Tubes (Al3003-O)
}

\author{
Changwan Han ${ }^{1}$, Hanjong Kim ${ }^{1}$, Jae-Hoon Lee ${ }^{2}$, Jihwan Park³ , and Seonghun Park ${ }^{1}$ \\ ${ }^{1}$ Pusan National University \\ ${ }^{2}$ Korea Marine Equipment Research Institute \\ ${ }^{3}$ hyundai core motion
}

May 5, 2020

\begin{abstract}
The purpose of this study is to analyze the effects of surface defects (e.g., notches) and external environment conditions (e.g., operating temperature, the number of re-welding) on the static strength and fatigue of Al3003-O aluminum tubes used in the heat exchangers of air conditioners. In this study by the aluminum tubes to perform fatigue tests on the actual tube product and then the fatigue characteristics were evaluated using stress-life $(\mathrm{S}-\mathrm{N})$ curves. Regarding the welding conditions (maximum 600 ${ }^{\circ} \mathrm{C}$ and $10 \mathrm{~s}$ ), the grain size grew and the hardness decreased as the number of re-welding increased. The effects of the operating temperatures on the fatigue life were examined at a room temperature of $25{ }^{\circ} \mathrm{C}$ and a heat exchanger operating temperature of $125{ }^{\circ} \mathrm{C}$, resulting in the fatigue $\operatorname{limit}(57.19 \mathrm{MPa}->49.02 \mathrm{MPa})$ at operating temperature was lower than room temperature. Furthermore, the fatigue limit of $29.37 \mathrm{MPa}$ measured in the notched specimens (notch angle of $90 @$, notch radius of $0.02 \mathrm{~mm}$, and depth of $0.115 \mathrm{~mm}$ ) was lower than that obtained from those without notches. The material constant (0.03) used in the Peterson equation was then computed from the fatigue notch factor $(1.67=49.02 / 29.37)$ and the stress concentration factor (2.73) of the notched tube specimens was obtained from the structural analysis. This material constant can be used to predict a decrease in the fatigue limit over varying notch sizes in aluminum tubes (Al3003-O).
\end{abstract}

\section{Introduction}

Heat exchanger tubes are hollow cylinders that transport liquids between devices placed in different positions, and commonly composed of cast iron, steel, copper, aluminum, and rubber ${ }^{1}$. Regarding tube materials, although copper has popularly been used, aluminum has currently been considered copper's replacement due to its cheaper production cost and high anticorrosive property, light weight and high productivity, compared to copper. Aluminum tubes are one-fourth times cheaper and $35 \%$ lighter than copper tubes ${ }^{2,3}$. In the operation of air conditioners, aluminum tubes are not subject to high loads or high stresses. However, notches and other surface defects occur frequently when the tubes undergo various heat-exchanger manufacturing processes. After the heat exchanger products are manufactured and installed in air conditioners, the tubes become exposed to long-term vibration and thermal loads. Thus, they must be inspected for fatigue failure in order to enhance their overall structural reliability ${ }^{4,5}$.

In previous studies, Gerber et al. claimed that fatigue tests must be conducted in consideration of actual operating conditions because the fatigue life can be affected when the material properties change under varying conditions (high temperature or high pressure) even if pressure boundary components are conservatively designed $^{6}$. Choi et al. performed bending fatigue tests on standard specimens extracted from steel tube products against actual tube products, and found that the actual tubes had a significantly shorter lifetime ${ }^{7,8}$. 
Fatigue tests on standard specimens are generally performed from a material perspective ${ }^{9-11}$. However, in order to determine the effects of the surface finishes, heat treatments, and operating environments on fatigue lives, several studies conducted fatigue tests on actual tube products ${ }^{12,13}$.

Standard specimens are different from actual tube products in terms of the material distribution in the inner/outer components and external appearance depending on the manufacturing process. For instance, tubes used in the heat exchangers of air conditioners are obtained by the extruding and drawing of raw materials. These processes result in differences in material uniformity, which subsequently affect various properties including surface roughness and hardness ${ }^{14-16}$. Furthermore, when heat exchanger tubes are eventually installed to the final air conditioner products through further processes such as bending, cutting, and welding, they cause defects such as notches and grooves on the tube surface as well as non-uniform material properties. It leads to the tubes to have different fatigue characteristics from those of standard specimens. Therefore, less accurate fatigue characteristics are obtained when using standard specimens, and it can be difficult to design products that satisfy external operating requirements based on these results ${ }^{17,} 18$. When examining the effects of these defects and the external environments on the fatigue lives of aluminum tubes used in heat exchangers of air conditioners, it is necessary to conduct a quantitative analysis using the actual tubes instead of standard specimens.

The purpose of this study is to analyze how fatigue characteristics and material properties are influenced by the defects arising due to the processing and assembling of Al3003-O aluminum tubes for heat exchangers in air conditioners. This study also considers the environmental factors affecting heat exchanger tubes. Notches such as scratches and dents on the tube surface significantly reduce the fatigue life of tubes. However, because it is possible to reduce such defects by employing materials with high hardness, the correlation between changes in grain size and the hardness of aluminum tubes due to the number of re-weldings that could occur during installation into air conditioners. Fatigue tests were performed on Al3003-O aluminum tubes instead of standard specimens, and the resulting stress-life $(\mathrm{S}-\mathrm{N})$ curves for the actual tubes were obtained. Furthermore, the effects of high-temperature $\left(125{ }^{\circ} \mathrm{C}\right)$ and notches on the fatigue lives of aluminum tubes that could occur during the manufacturing and operation of heat exchangers were assessed.

\section{Hardness tests and grain size analysis as a function of repeated welding cycle}

An air conditioner consists of an indoor unit responsible for controlling the indoor air conditions and an outdoor unit that rejects heat to the external environment. The two units are connected using aluminum tubes. Welding of the aluminum tubes is performed during the installation of an air conditioner, and welding is repeated for the purpose of re-installation and repairs. This may cause structural changes in the material of the tubes, and such changes can be observed in the grain size. The material quality should be maintained by maintaining the grain size at a certain level because a larger grain size lowers the yield strength, hardness, and fatigue life of the tubes. In this study, the correlation between the grain size and hardness in relation to the number of re-weldings of the aluminum tubes was analyzed.

\subsection{Aluminum tube specimens}

Aluminum tubes (Al3003-O) used in this study, created via processes such as extruding and drawing. They are widely used in heat exchangers of air conditioners, as they are excellent formability and corrosion resistance (Table 1).

\subsection{Specimen preparation for hardness tests and grain size analysis}

Specimens were prepared for the measurement of the grain size and hardness in relation to the number of re-weldings of the aluminum tubes. Welding was defined as heating the surface of the aluminum tubes 
with a torch for $10 \mathrm{~s}$, followed by air cooling for $1 \mathrm{~h}$. Two pairs of the specimens were prepared, and each pair was welded 0,1 , and 5 times, respectively, in order to obtain a total of 12 specimens. Considering the actual installation environment, the test conditions were set such that welding could be repeated up to a maximum of 5 times. To measure the grain size and hardness, the torched area was cut, and epoxy molded specimens were prepared a molding solution containing an epoxy and a hardener at a ratio of 12.5 to 2 . Because bubbles tend to form when diluting the epoxy and the hardener, the epoxy molding specimens were placed in a vacuum chamber for $120 \mathrm{~s}$ to eliminate the bubbles. The specimens were sandpapered from \#400 to \#2400 sandpapers and polished with $1 \mu \mathrm{m}$ abrasives on a soft abrasive cloth. The polished side was placed in a solution of $200 \mathrm{ml}$ distilled $\mathrm{H} 2 \mathrm{O}$, and $5 \mathrm{ml} \mathrm{HBF} 4$ for $180 \mathrm{~s}$ and then washed under running water to completely remove the etching solution. After neutralizing the specimens in an alkaline aqueous solution, they were sufficiently dried and readied for the grain size and hardness measurements (Fig. 1).

\subsection{Hardness tests, grain size analysis, and the results}

The grain size on the etched surface of the specimens was observed using a metallurgical microscope (Nikon, MA200, Japan); images were captured at a magnification of 100x. The grain size $\left(D_{m}\right)$ was calculated using the linear intercept method specified in ASTM E112 ${ }^{19}$; grain size was calculated by counting the number of grains $(n)$ from 5 parallel lines of length $\mathrm{L}(\mathrm{mm})$ in the metallurgical microscope image (Fig. 3), and the average grain size was obtained by rounding up from the hundredths place in the following equation (1).

$$
D_{m}=\frac{L \times P}{n \times M}
$$

where $P$ is the number of parallel lines and $M$ is the magnification. A micro-Vickers hardness tester (HM200, Mitutoyo, Japan) was used to measure the hardness of the aluminum tubes in relation to the number of re-weldings. The micro hardness at 20 points or 10 points, each on the upper and lower thickness areas, was measured while maintaining the load at $100 \mathrm{gf}$ for $10 \mathrm{~s}$ (Fig. 2).

From the measurement of the structure of the heat-affected zone in relation to the number of re-weldings of the aluminum tubes, the grain size was found to be $99.82 \pm 9.72$ ( $\mathrm{n}=16: 4$ test specimens $\mathrm{x} 4$ positions) for the unheated specimens, $122.87+-7.33$ ( $\mathrm{n}=16: 4$ test specimensx 4 positions) when the specimens were heated once, 174.32+-36.45 ( $\mathrm{n}=16: 4$ test specimensx4 positions) when the specimens were heated five times (Fig. 3 , Table 2). Thus, the grain size increased with the number of re-weldings. Hardness measurements were taken to examine the changes in the mechanical properties. The hardness was $40.72+-0.45 \mathrm{Hv}(\mathrm{n}=80: 4$ test specimens $\mathrm{x} 20$ points) for the unheated specimens, $36.61+-0.41 \mathrm{Hv}(\mathrm{n}=80: 4$ test specimensx20 points) when the specimens were heated once, $34.49+-0.40 \mathrm{Hv}$ ( $\mathrm{n}=80: 4$ test specimensx20 points) when the specimens were heated five times. A one-way analysis of variance (one-way ANOVA) was performed to investigate the effect of re-welding on the hardness with a significance level of 0.05 using Microsoft Excel (Microsoft, USA).Statistically significant differences in the hardness values were observed in all cases $(p<0.05)$. This result indicates that the hardness decreases as the number of re-welding increases (Fig. 3, Table 2).

Based on the above observations, the correlation between the hardness $\left(H_{v}\right)$ and the grain size $(d)$ was given by the following equation (Fig. $4(\mathrm{a}), R^{2}=0.999$ ),

$H_{v}=232.87 \times \exp \left(-\frac{d}{28.12}\right)+34.02(2)$

The unheated specimens had a hardness of $40.72 \mathrm{Hv}$ for a grain size of 122.87 , while those heated once had a much smaller hardness of $36.61 \mathrm{Hv}$ for a grain size of 174.32 . With re-weldings, the decrease in the hardness was less prominent than the decrease in the grain size and gradually converged over time.

We have also tried to relate the hardness $\left(H_{v}\right)$ and the grain size $(d)$ by the well-known Hall-Petch equation (Fig. 4(b), $\left.R^{2}=0.866\right),{ }^{20}$

$H_{v}=15.72+243.40 \times d^{-0.5}(3)$ 


\section{Fatigue tests of aluminum tubes}

Rotary bending fatigue tests were performed at the room temperature of $25 \operatorname{deg} \mathrm{C}$ and an operating temperature of $125 \mathrm{degC}$ to evaluate the effects of the operating environment on the fatigue life of the aluminum tubes. To determine the effects of surface defects occurring during product assembly, V-notches were fabricated on the aluminum tubes for the fatigue tests. The notch sensitivity and material constant used in the Peterson equation were then computed from the fatigue notch factor and the notched tube specimens' stress concentration factor obtained from the structural analysis.

\subsection{Fatigue test specimens}

\subsubsection{Smooth un-notched and notched tube specimens for fatigue tests}

In general, rotary bending fatigue tests involving tube-shaped specimens; the jaw of the fatigue test machine is tightened around both ends of specimen to prevent slip. To perform fatigue tests on tube-shaped specimens using a rotary bending fatigue test machine, metal plugs were inserted into both ends of the aluminum tubes and the specimens were mounted on the jaw. The aluminum tube specimens were designed to undergo fatigue failure at their central area during the fatigue tests.

Static structural analysis was conducted to determine the location of the fatigue failure that occurs when metal plugs are inserted into the aluminum tubes in the unprocessed state. A 3D model was created in the commercial finite element analysis package ANSYS (V19.1, USA) for the aluminum tubes; the external diameter of the tube was $15.88 \mathrm{~mm}$ and its thickness was $1.9 \mathrm{~mm}$, and metal plugs were inserted into both its ends. Symmetric boundary conditions were applied, and the analysis was performed using a 1/4 model. A mesh was generated using hexahedral elements from the 3D model; the number of nodes and elements produced were 30,000 and 10,000, respectively. In accordance with online database MatWeb, the aluminum tubes used in the structural analysis had a modulus of elasticity of $125 \mathrm{GPa}$ and a Poisson's ratio of 0.33 . In our previous study, tensile tests were conducted at room temperature to obtain the load-displacement curves of the Al3003-O aluminum tubes, and the tensile strength and yield strength were derived using stress-strain curves acquired from tensile tests. The basic structural steel provided in ANSYS was used as the material of the metal plug. As the boundary condition, a bending moment of $300 N^{*} \mathrm{~mm}$ was introduced at one end of the tubes (Fig. 5).

The structural analysis of the tubes in the unprocessed state showed that fractures did not occur at the center of the tubes owing to a uniform distribution of high stress even at the surface (Fig. 6(a)), and the distribution of fractures during the fatigue tests was thus assumed to be random. Therefore, considering the site of distribution of high stress on the surface, it was designed as a concave test specimen(R $200 \mathrm{~mm}$ ) whose tube center thickness was reduced to $0.94 \mathrm{~mm}$. The previously mentioned boundary conditions were assigned to the finite element model to determine whether fractures occurred at the centers of the tubes. The specimens were then fabricated using the design, which exhibited high stress mostly in the central area (Fig. 6(b)).

\subsubsection{Notched tube specimens for fatigue tests}

Owing to their geometric characteristics, surface defects (surface scratches, dents, etc.) occurring in aluminum tubes used to manufacture heat exchangers in air conditioners induce stress concentration and lower fatigue life. To predict the fatigue life in relation to surface defects, notched tube fatigue specimens were prepared by introducing $\mathrm{V}$-notches in the aforementioned tube specimens, where a surface dent is defined as a dent having a notch angle of $90 @$, a notch radius of $0.02 \mathrm{~mm}$, and a depth of $0.115 \mathrm{~mm}$ (Fig. 7). 


\subsection{Rotary bending fatigue tests}

A four-point rotary-bending fatigue-test equipment (KDMT-250, Korea) was used for the fatigue test (Fig. 8). The stress ratio was -1 because the mean stress of the cyclic loading profiles was 0 in the rotary bending test. After locking the specimens, the eccentricity was measured using a dial gauge to ensure a value of 0.05 $\mathrm{mm}$ or less; the frequency of rotations was set as $1800 \mathrm{rpm}$. The bending stress experienced by the tubes due to the bending load was calculated as shown by

$$
\sigma_{\max }=\frac{16 \times D \times L \times P}{\pi\left(D^{4}-d^{4}\right)}(4)
$$

where $P$ is the load of the pendulum, $\mathrm{L}$ is the distance between loading points (200 $\mathrm{mm}$ ), and $d$ and $D$ are the internal and external diameters of the aluminum tubes, respectively. The digital caliper(Mitutoyo, Japan) was used to accurately measure the internal and external diameters of the tubes. The fatigue test was performed while varying the stress under two temperatures $\left(25^{\circ} \mathrm{C}\right.$ and $125^{\circ} \mathrm{C}$ ) and notched (notch angle of $90 @$, notch radius of $0.02 \mathrm{~mm}$, and depth of $0.115 \mathrm{~mm}$ ) conditions. The fatigue tests were performed for a total of 10 specimens. Each test was concluded when the specimens experienced fractures or reached the fatigue limit $\left(1 \times 10^{7}\right.$ cycles $)$. As predicted from the specimen design, fractures were observed in the central areas of the specimens (Fig. 8).

\subsection{Fatigue test results}

\subsubsection{Comparison of fatigue life at $25 @ \mathrm{C}$ and $125 @ \mathrm{C}$}

The S-N curves for the aluminum tubes were obtained at room temperature $\left(25^{\circ} \mathrm{C}\right)$ and at the heat exchanger operating temperature of $125{ }^{\circ} \mathrm{C}$ (Fig. 9(a)). Based on the S-N curves at the two temperatures, a linear equation was obtained on the $\log -\log$ scale and converted to a decimal scale as follows.

Temperature of $25^{\circ} \mathrm{C}: S_{\max }=113.96 \times N_{f}^{-0.043}(5)$

Temperature of $125^{\circ} \mathrm{C}: S_{\max }=108.97 \times N_{f}^{-0.050}(6)$

The fatigue limits (defined as the stress at $1 \times 10^{7}$ cycles) were $57.19 \mathrm{MPa}$ at $25^{\circ} \mathrm{C}$ and $49.02 \mathrm{MPa}$ at 125 ${ }^{\circ} \mathrm{C}$, resulting in a temperature modification factor of 0.86 , which was calculated by dividing the fatigue limit at $125{ }^{\circ} \mathrm{C}$ by that at $25^{\circ} \mathrm{C}$.

The results of the fatigue tests in relation to notches in the aluminum tubes are shown in Fig. 9(b). As explained earlier, the $\mathrm{S}-\mathrm{N}$ curve was fitted by the following equation.

$$
\text { Temperature of } 125{ }^{\circ} \mathrm{C} \text {, notched: } S_{\max }=49.058 \times N_{f}^{-0.032}(7)
$$

The fatigue limit, which was defined as the fatigue strength at $1 \times 10^{7}$ cycles, was found to be $29.37 \mathrm{MPa}$. The alternating stress value for the notched specimen was lower than those of the smooth specimens. The notch modification factor, which was calculated by dividing the fatigue limit of the notched specimens by that of the smooth specimen(results of heat exchanger operating temperature of $125^{\circ} \mathrm{C}$ ), was 0.60 , resulting in a fatigue notch factor $\left(K_{f}\right)$ of 1.67 that is an inverse of the notch modification factor.

\subsubsection{Determination of material constant}

By deriving the material constant $(a)$ from the Peterson equation, we can estimate the fatigue notch factor $\left(K_{f}\right)$ under different notch conditions. First, the stress concentration factor was obtained for notched tubes through a structural analysis in ANSYS (V19.1, USA). V-notches, measuring notch angle of $90 @ 0.02 \mathrm{~mm}$ in notch radius, and $0.115 \mathrm{~mm}$ in depth, were introduced onto standard smooth specimens, and a bending moment of $300 \mathrm{~N} \cdot \mathrm{mm}$ was applied to one end of the tubes. The results of the structural analysis showed that the notched specimens had a maximum stress of $13.69 \mathrm{MPa}$ (Fig. 10). The stress concentration factor, which was calculated using the ratio of the average stress (5.02 MPa) in standard un-notched specimens to that of notched specimens, was found to be 2.73 . 
When the stress concentration factor $\left(K_{t}=2.73\right)$ of the notched tube specimens was obtained through structural analysis, and the notch radius $(r=0.02 \mathrm{~mm})$ and the fatigue notch factor, which were calculated based on the results of fatigue tests $\left(K_{f}=1.67\right)$, were substituted into the Peterson equation (Eq. (8)), the material constant $(a)$ was found to be $0.03 \mathrm{~mm}$. Therefore, because $K_{f}$ in relation to the notch radius $(r)$ can be easily obtained by the Peterson equation,

$K_{f}=1+\left(\frac{K_{t}-1}{1+\frac{a}{r}}\right)$

it is possible to predict the decrease in the fatigue limit due to various notch sizes.

\section{Discussion}

The purpose of this study was to analyze the effects of surface defects (notches), operating temperature, and the number of re-welding on the static strength and fatigue characteristics of the aluminum tubes (Al3003$\mathrm{O})$ used in heat exchangers of air conditioners. In the present study, the grain size grew and hardness decreased as the number of re-welding increased because a heat-affected zone was created in the specimens due to a welding temperature of approximately 600 and multiple weldings. The result that the correlation between the grain size and the hardness was observed to be nonlinear suggests that the heat-affected area of the aluminum tubes shows a significant deterioration in the hardness even when welded only once; this is expected to be accompanied by a decrease in the mechanical strength. As repeated welding causes the strength of the aluminum tubes to decrease further, in order to avoid the creation of more heat-affected zones, it is better to add new tubes or to extend existing ones instead of repeatedly welding the same area. Regarding the underlying mechanism of the relation between the hardness and the grain size, the density of the grain boundary generally decreases with increasing grain size, and hence, the hardness decreases owing to the increased mobility of dislocation. In other words, grain boundary acts as an obstacle to dislocation movement. The smaller the grain size, the more grain boundary exists. As a result, the movement of dislocation is disturbed and the hardness increases.

Moreover, the relation between the mechanical strength (i.e., yield stress) and grain size of a metal has previously been formulated by the Hall-Petch equation, $\sigma_{y}=\sigma_{o}+k_{y} d^{-0.5}$ where $\sigma_{y}$ is the yield stress, $\sigma_{o}$ is the stress for dislocation motion, $k_{y}$ is a material constant, and dis the grain size. In the absence of considerable work hardening effect of material, this equation can be modified to relate the hardness $\left(H_{v}\right)$ and grain size (d) by $H_{v}=H_{o}+k_{H} d^{-0.5}$ where $H_{o}$ and $k_{H}$ are material constants. According to the Hall-Petch equation, the mechanical strength can be directly converted to the hardness. Therefore, a decrease in the hardness with increasing number of re-welding makes the material less strong and more ductile. This result can affect the fatigue strength of the material. It has been well known that ductile material generally provides a good fatigue resistance in the low-cycle fatigue region where most of the fatigue life is occupied by the crack propagation than crack nucleation due to a considerable amount of plastic deformation. Furthermore, in the present study, when unheated, the hardness of the material is based on both work hardening and grain size, but materials with heat history ( 0,1 and 5 times re-weldings) are re-crystallized, thus the hardness values are related only to the grain size. Nevertheless, the current results showed a poor correlation $\left(R^{2}=0.866\right)$ between the hardness $\left(H_{v}\right)$ and grain size $\left(d^{-0.5}\right)$ by the Hall-Petch equation, indicating that the hardness would be better related to the grain size by the equation, $H_{v}=H_{o}+k_{H} d^{-\alpha}$ which has three parameters $\left(H_{o}, k_{H}\right.$, and $\left.\alpha\right)$.

The effects of temperature and notched conditions on the fatigue of the Al3003-O aluminum tubes used in heat exchangers of air conditioners were also observed. The fatigue limit of $49.02 \mathrm{MPa}$ measured in a heat exchanger operating temperature of $125 \operatorname{deg} \mathrm{C}$ was lower than that obtained from those with at a room temperature of $25 \mathrm{degC}$, resulting in a temperature modification factor of 0.86 that the fatigue life of aluminum tubes of are affected even when the operating temperature $(125 \mathrm{deg} \mathrm{C})$ is maintained. The kinetic energy of molecules in the aluminum tube rises whose generates an active molecular motion when the temperature increases. In particular, the spacing between molecules is increased which results in a 
lower binding force, the probability of breaking the bond between molecules increases when an external load is applied. Therefore, the grain size increases at the high temperatures a thereby the slip deformation accelerates and a significant deterioration of fatigue strength of aluminum tubes. However, the fatigue limit of notched specimens was lower than that of un-notched specimens, thus resulting in a fatigue notch factor of approximately $K_{f}=1.67$. From this fatigue notch factor obtained from experimental measurements and the stress concentration factor $\left(K_{t}=2.73\right)$ of the notched tube specimens $(r=0.02 \mathrm{~mm})$ obtained from structural analysis, the material constant $a=0.03 \mathrm{~mm}$ that could be used in the Peterson equation was computed. Therefore, for Al3003-O aluminum tubes with diverse notch sizes, it is possible to predict $K_{f}$ that leads to calculations of decreased fatigue limits due to various notch sizes. For example, for another notch size of $r=0.5 \mathrm{~mm}, K_{t}$ can be computed from structural analysis. Then, by inserting this $K_{t}, r=0.5$ $\mathrm{mm}$, and $a=0.03 \mathrm{~mm}$ into the Peterson equation, $K_{f}$ for this notch size can be calculated. By using the material constant a of the aluminum tubes (Al3003-O) calculated in this study, the fatigue notch factor $K_{f}$ can be re-calculated for the aluminum tubes with varying notch sizes $(r)$, and hence a decrease in the fatigue limit can also be predicted for those aluminum tubes with diverse notches.

\section{Conclusions}

The current study addressed how the static and fatigue strength of Al3003-O aluminum tubes used in air conditioner heat exchangers could be affected by their multiple weldings, operating temperatures, and surface notches. A nonlinear decrease in the hardness of the aluminum tubes with increasing number of re-welding observed experimentally suggests a decrease in their fatigue limits with multiple weldings. The fatigue lives of an aluminum tube at heat exchanger operating temperature $(125 \mathrm{deg}$ ) were lower than that of room temperature. Moreover, a decrease in the fatigue limit of the aluminum tubes was experimentally measured in the presence of a surface notch and, combined with this experimental measurement, a method to predict a decrease in the fatigue limits for other surface notch sizes was also presented.

\section{Acknowledgments}

This research was supported by the National Research Foundation of Korea (NRF) grant funded by the Korea government (MSIP) (No. NRF-2016R1A2B4012561), by Engineering Development Research Center (EDRC) funded by the Ministry of Trade, Industry \& Energy (MOTIE) (No. N0000990), and by "Human Resources Program in Energy Technology" of the Korea Institute of Energy Technology Evaluation and Planning (KETEP) granted financial resource from the Ministry of Trade, Industry \& Energy, Republic of Korea (No. 20164030201230).

\section{References}

1. Park S, Kwon HH, Koo JM, Seok CS, Jung DH, Mo JY (2012) A Study on the fatigue life prediction for bending pipe. Advanced Materials Research . Trans Tech Publ, 2219-2225.

2. SAPA_GROUP (2013).

3. Kwon H, Kim K-H, Han C, Park S (2017) A new methodology for detecting adhesion location in aluminum tube expansion. Advances in Mechanical Engineering . 9 : 1687814017731039.

4. Rahman S, Wilkowski G, Mohan R (1997) Low-cycle fatigue crack growth considerations in pipe fracture analyses. Nuclear engineering and design . 168 : 105-118.

5. Rahman M, Hossain M, Rahman S (1999) Stress concentration incorporated fatigue analysis of die-marked drill pipes. International journal of Fatigue. 21 : 799-811. 
6. Gerber D (1998) Evaluation of environmental fatigue effects for a Westinghouse nuclear power plant.EPRI Report No TR-110043.

7. Seok CS, Park JS, Kim HI, Lee YM, Cho WH, Song WK (2005) Evaluation of fatigue characteristic of a real waterworks pipe. Key engineering materials . Trans Tech Publ, 2471-2476.

8. Choi J-H, Koo J-M, Seok C-S, Song W-K (2008) Evaluation of fatigue life characteristic of a real waterwork pipe using the probability density function. Transactions of the Korean Society of Mechanical Engineers A . $32: 707-712$.

9. Association A (2000) Aluminum Standards and Data, 2000 . Aluminum Association.

10. Stephens RI, Fatemi A, Stephens RR, Fuchs HO (2000) Metal fatigue in engineering. John Wiley \& Sons.

11. Davis JR (2001) Copper and copper alloys . ASM international.

12. Han H, Lee K, Park S, Park S, Song M (2015) The effect of baking time, fillet radius, and hardness on the lifecycles of pole fastening screws in an electric motor with hydrogen embrittlement. Engineering Failure Analysis .48: 62-77.

13. Park J-Y, Kim M-S, Oh C, et al. (2017) Solder joint fatigue life of flexible impact sensor module for automotive electronics. Korean Journal of Metals and Materials .55 : 232-239.

14. Yao W, Xia K, Gu Y (1995) On the fatigue notch factor, Kf. International Journal of Fatigue .17 : 245-251.

15. Kim JW, Park CY (2006) Experimental investigation of the failure behavior of notched wall-thinned pipes. Nuclear engineering and design . 236 : 1838-1846.

16. Bi Z, Pilkey WD, Pilkey DF (2020)Peterson's Stress Concentration Factors . John Wiley \& Sons.

17. Park JS, Seok C-S, Choi JH (2006) Fatigue life characteristics of waterworks pipe welds.International Journal of Modern Physics B . 20 : 3969-3974.

18. Choi J-H, Kim I-H, Koo J-M, Seok C-S (2010) A Study on Behavior of Mixed Mode Fatigue Crack Growth of Spiral Welding Part Under Bending Load. ASME 2010 Pressure Vessels and Piping Division/KPVP Conference. American Society of Mechanical Engineers Digital Collection, 459-463.

19. Subcommittee A (1996) Standard test methods for determining average grain size. ASTM International.

20. Furukawa M, Horita Z, Nemoto M, Valiev R, Langdon T (1996) Microhardness measurements and the Hall-Petch relationship in an Al? Mg alloy with submicrometer grain size.Acta Materialia . 44 : 4619-4629.

\section{Table captions}

Table 1 Chemical compositions(wt\%) of Al3003-O

\begin{tabular}{llllll}
\hline $\mathrm{Al}$ & $\mathrm{Cu}$ & $\mathrm{Fe}$ & $\mathrm{Mn}$ & $\mathrm{Si}$ & $\mathrm{Zn}$ \\
\hline $96.70 \sim 99.00$ & $0.05-0.20$ & {$[?] 0.70$} & $1.00-1.50$ & {$[?] 0.60$} & {$[?] 0.10$} \\
\hline
\end{tabular}

Table 2 Mean \pm standard deviation values of hardness and grain size in relation to the number of re-weldings of the Al3003-O tubes

\begin{tabular}{lll}
\hline Cycles & Hardness, $\mathrm{Hv}$ & Grain size $[d, \mu \mu]$ \\
\hline 0 & $40.72 \pm 0.45$ & $99.82 \pm 9.72$
\end{tabular}




\begin{tabular}{lll}
\hline Cycles & Hardness, Hv & Grain size $[d, \mu \mu]$ \\
\hline 1 & $36.61 \pm 0.41$ & $122.87 \pm 7.33$ \\
5 & $34.49 \pm 0.40$ & $174.31 \pm 36.45$ \\
\hline
\end{tabular}

\section{Figure captions}

Figure 1 Cross-sectional view of a aluminum tube specimen and its torched region for repeated welding cycles and cross-sectional view of epoxy molded specimen for hardness measurements

Figure 2 Ten positions of upper and lower regions of aluminum tube specimen for micro-Vickers hardness $(\mathrm{Hv})$ measurements

Figure 3 Grain size images for multiple welding cycles: (a) 0 cycle, (b) 1 cycle, and (c) 5 cycles

Figure 4 Correlation between hardness and grain size for repeated welding cycles

Figure 5 Finite element model and boundary conditions of aluminum tube specimen for fatigue tests

Figure 6 Results of structural analysis under bending moment condition with cutting thicknesses:

(a) Selection of cutting thickness in the unprocessed state $(\mathrm{t}=0.94 \mathrm{~mm})$, (b) Designed as a concave test specimen $(\mathrm{R} 200 \mathrm{~mm})$ whose tube center thickness was reduced to $0.94 \mathrm{~mm}$

Figure 7 Measurement of notch shape and size

Figure 8 Rotary bending fatigue test machine and representative fractured specimen after fatigue tests

Figure 9 (a) Fatigue test results at 25degC (black diamond, *) and 125degC (black triangle,

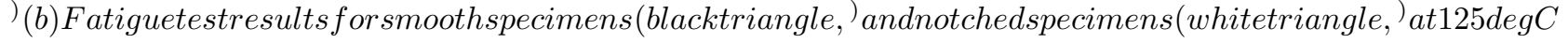

Figure 10 Maximum principal stress of notched tube specimen used to calculate material constant $(a)$ of the Peterson equation

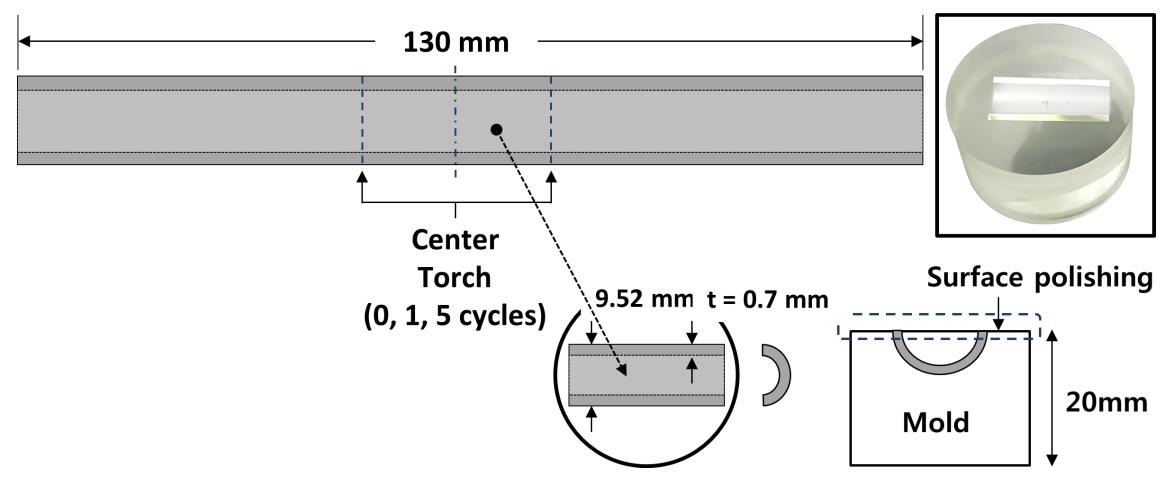




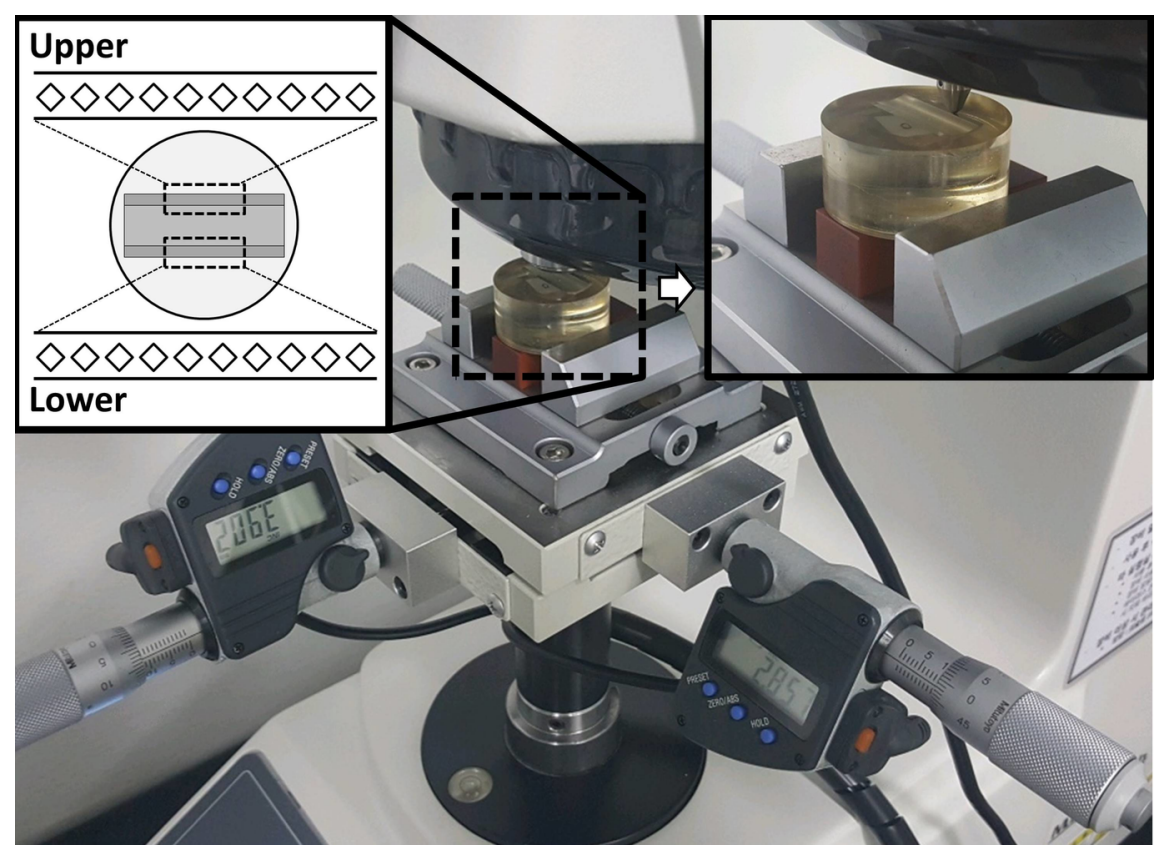




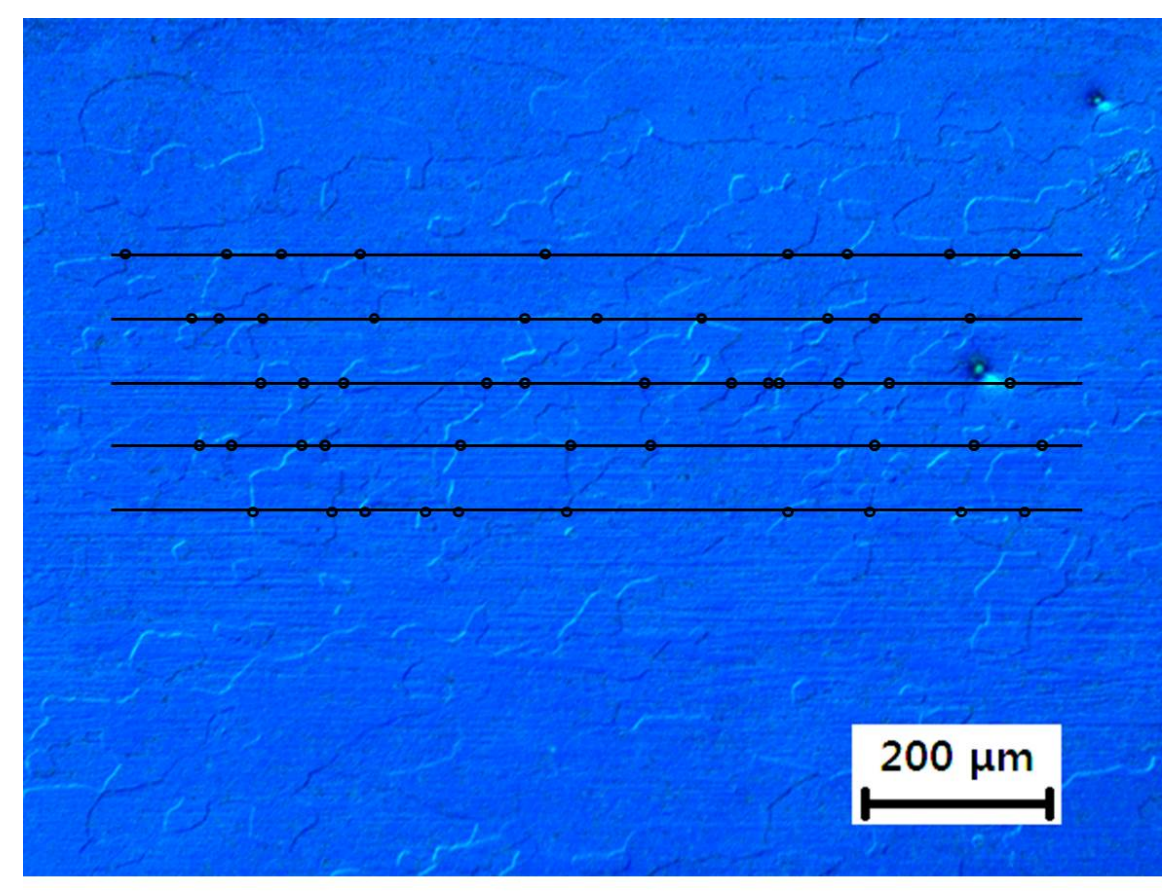

(a)

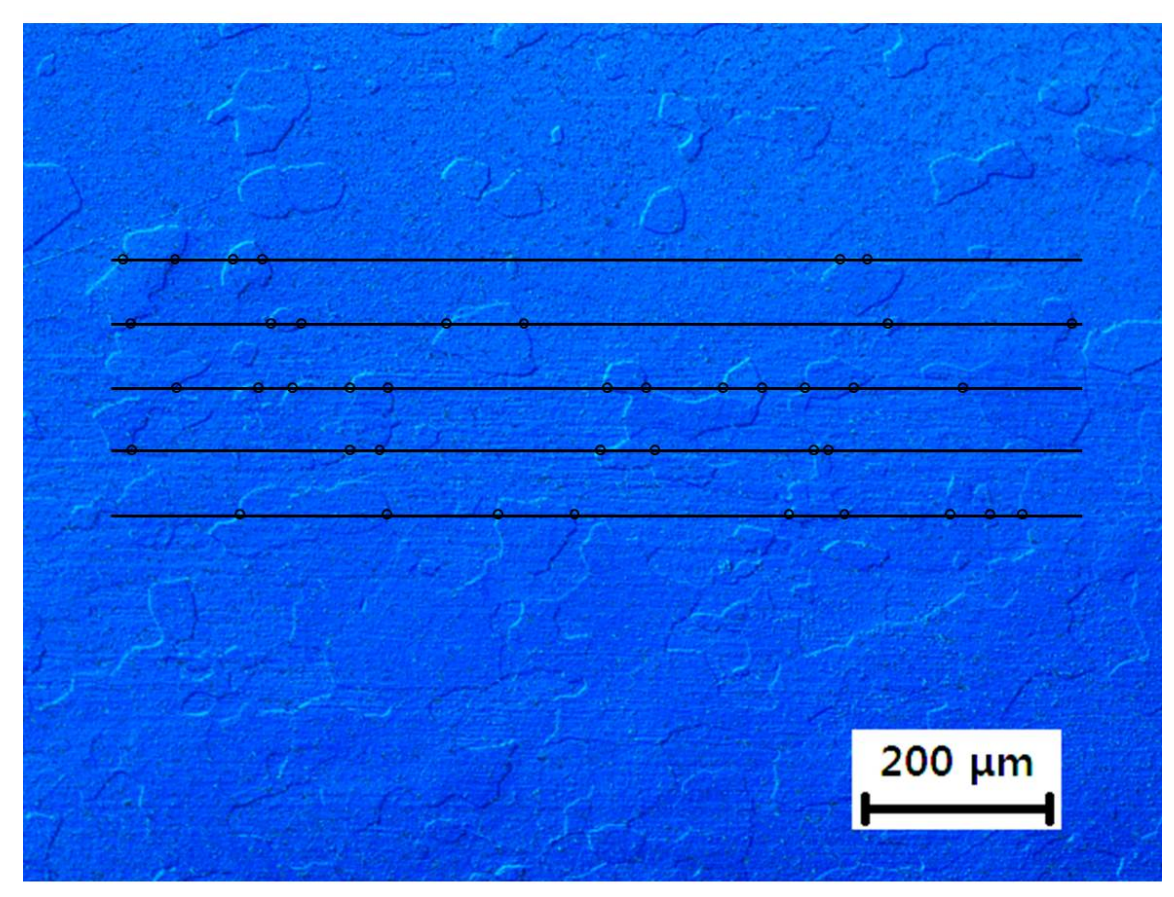

(b)

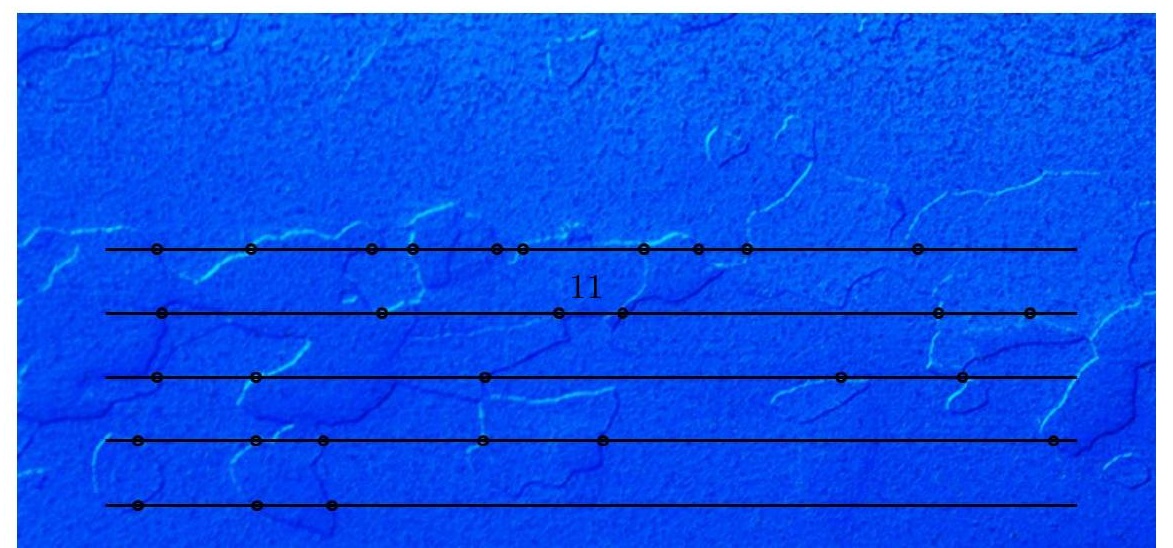




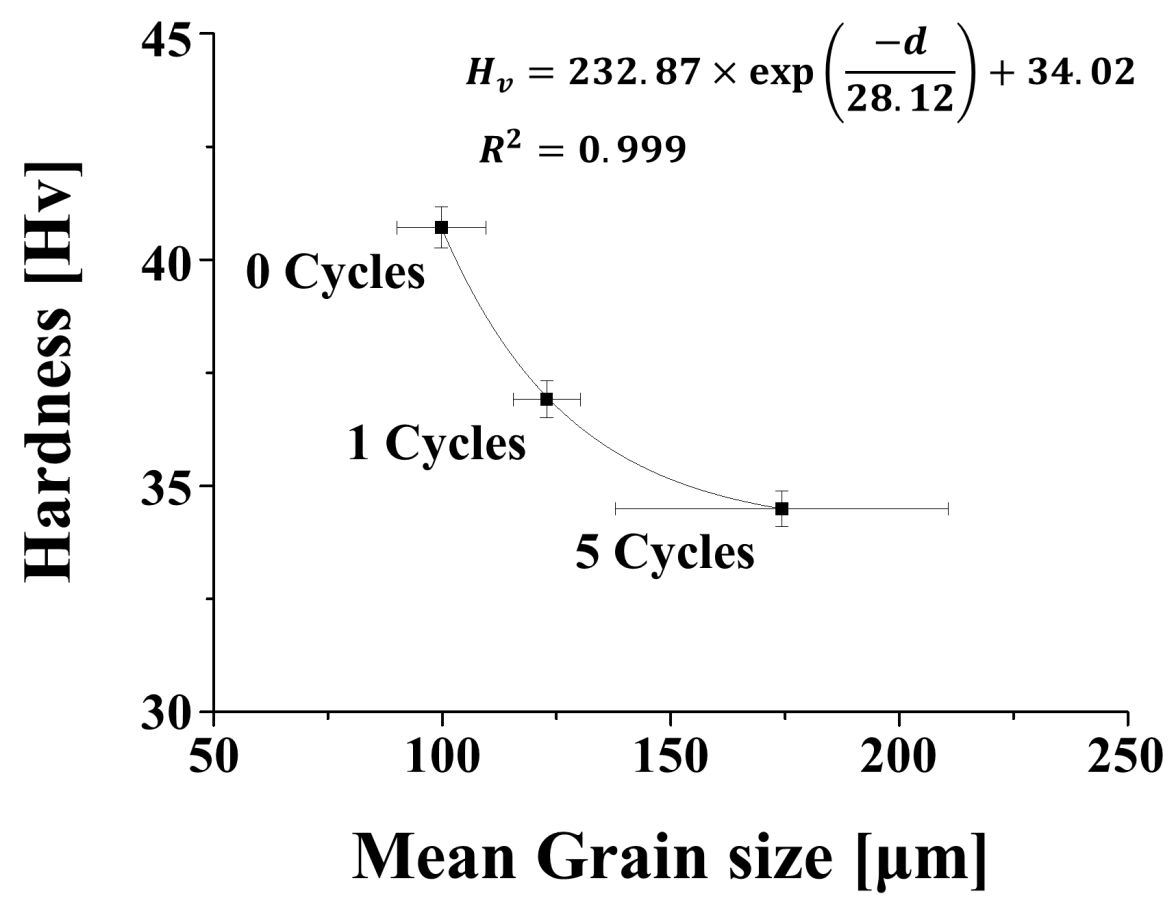

(a)

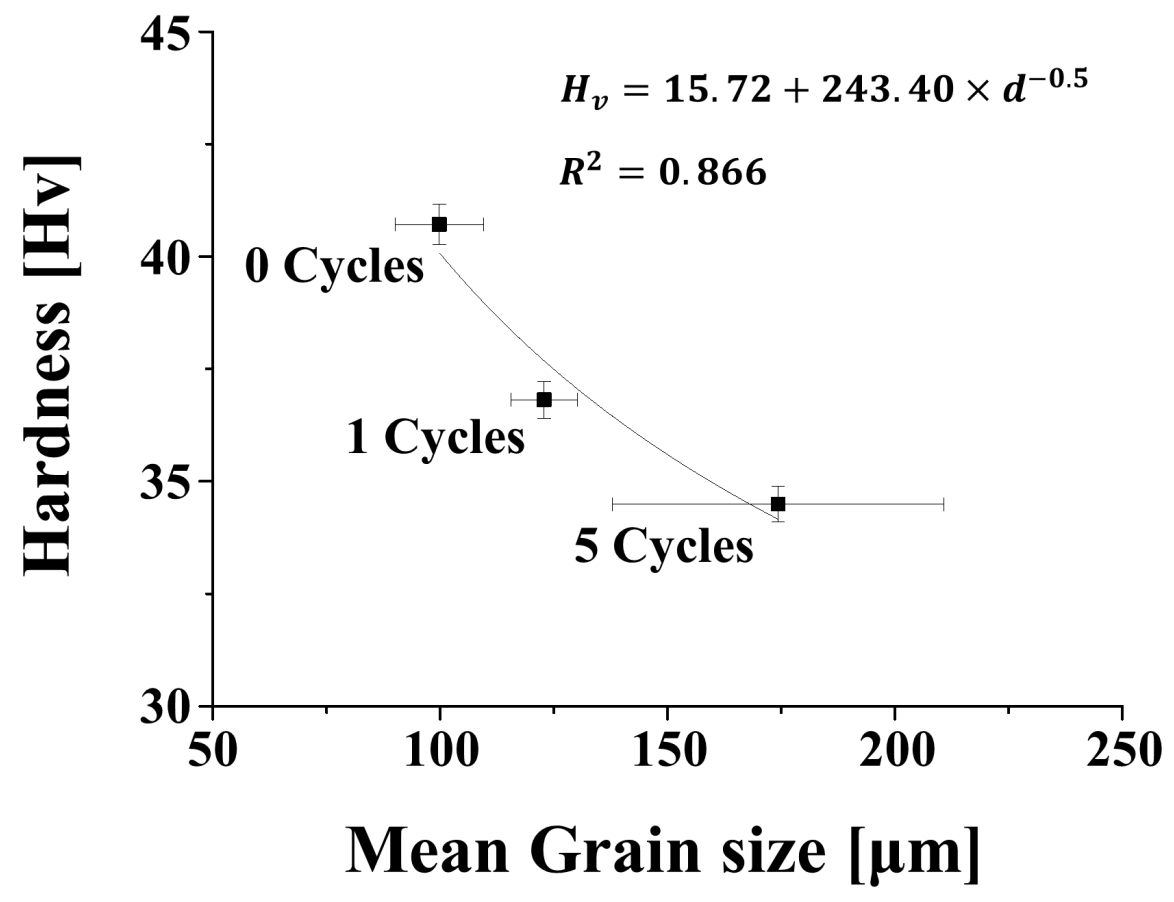

(b) 


\section{Symmetry}
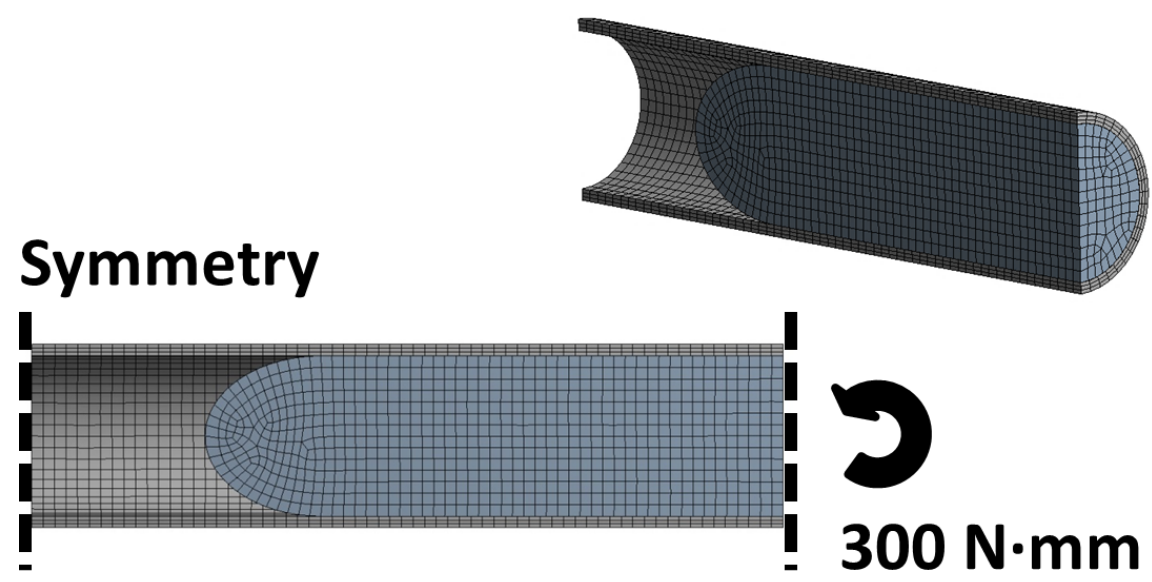

Type: Equivalent (von-Mises) Stress

Unit: MPa

\begin{tabular}{|l}
2.3346 Max \\
2.0752 \\
1.8158 \\
1.5564 \\
1.297 \\
1.0377 \\
0.77827 \\
0.51889 \\
0.25951 \\
0.00012819 Min
\end{tabular}

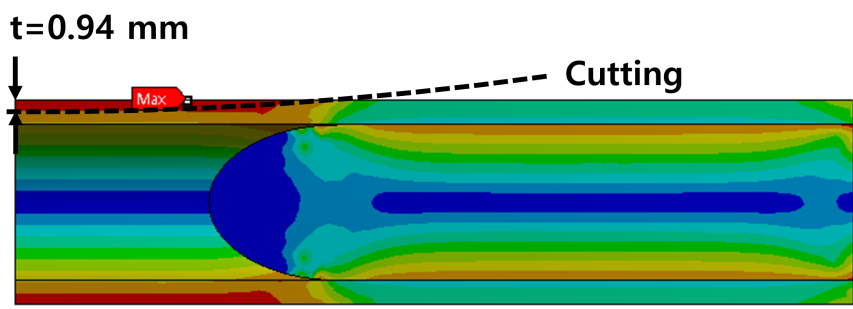

(a)

Type: Equivalent (von-Mises) Stress

Unit: MPa

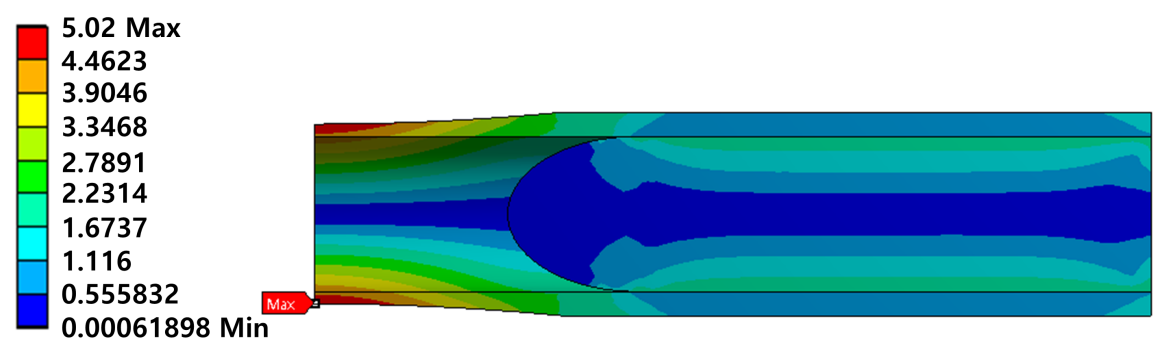

(b) 

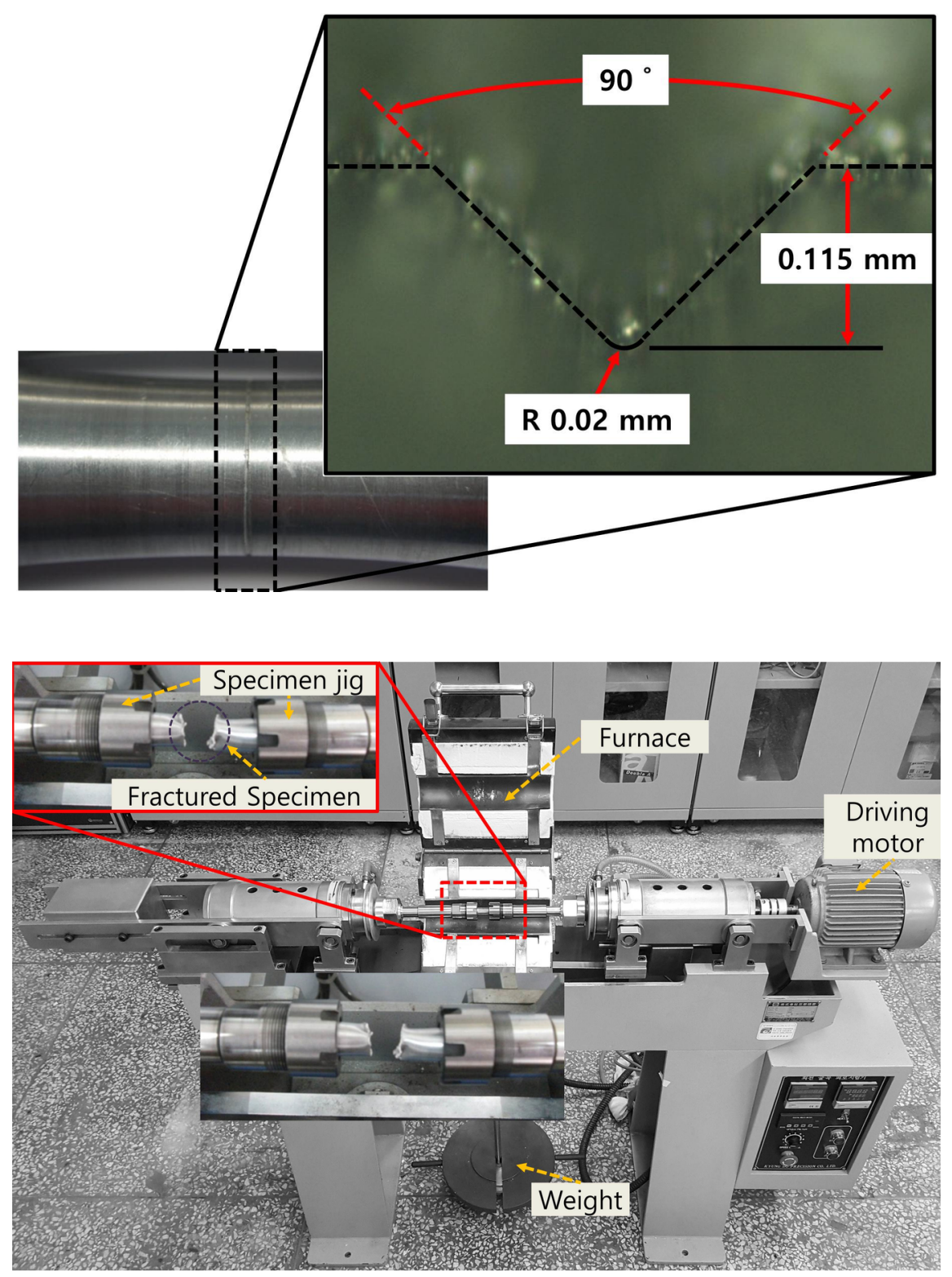


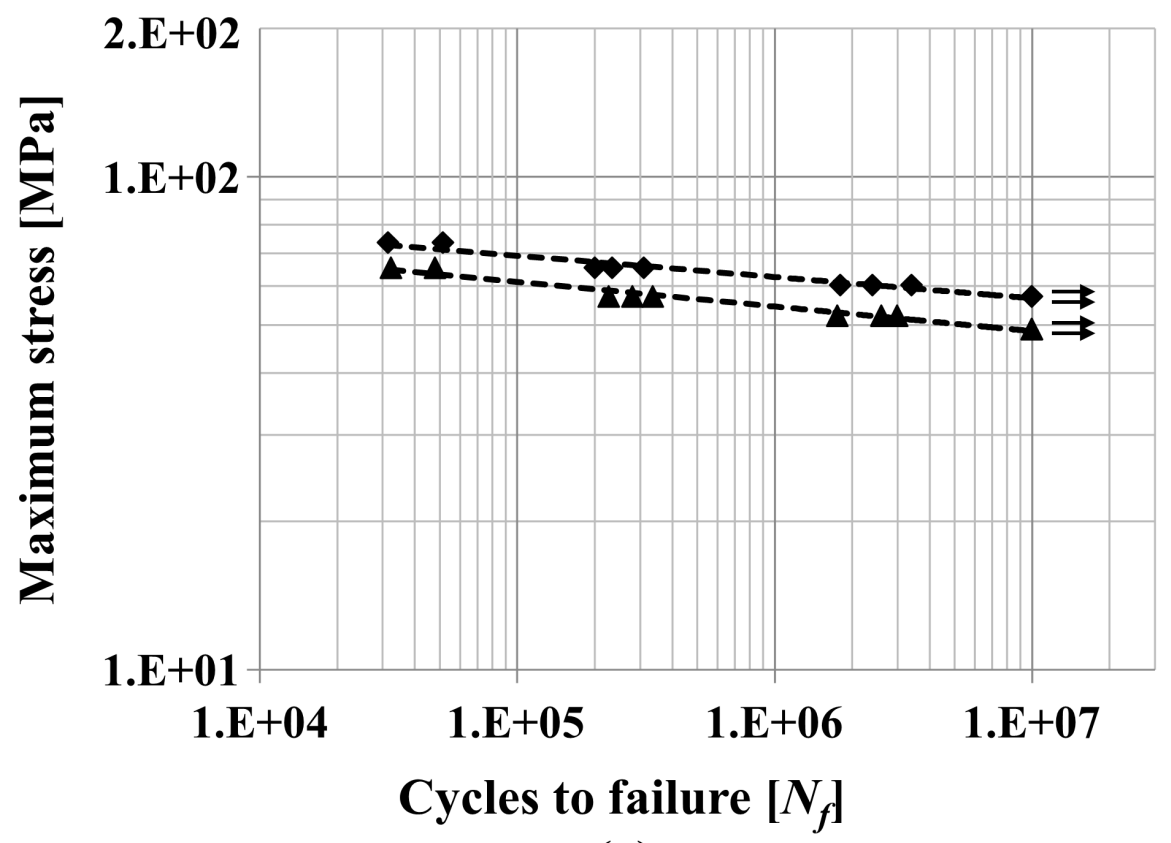

(a)

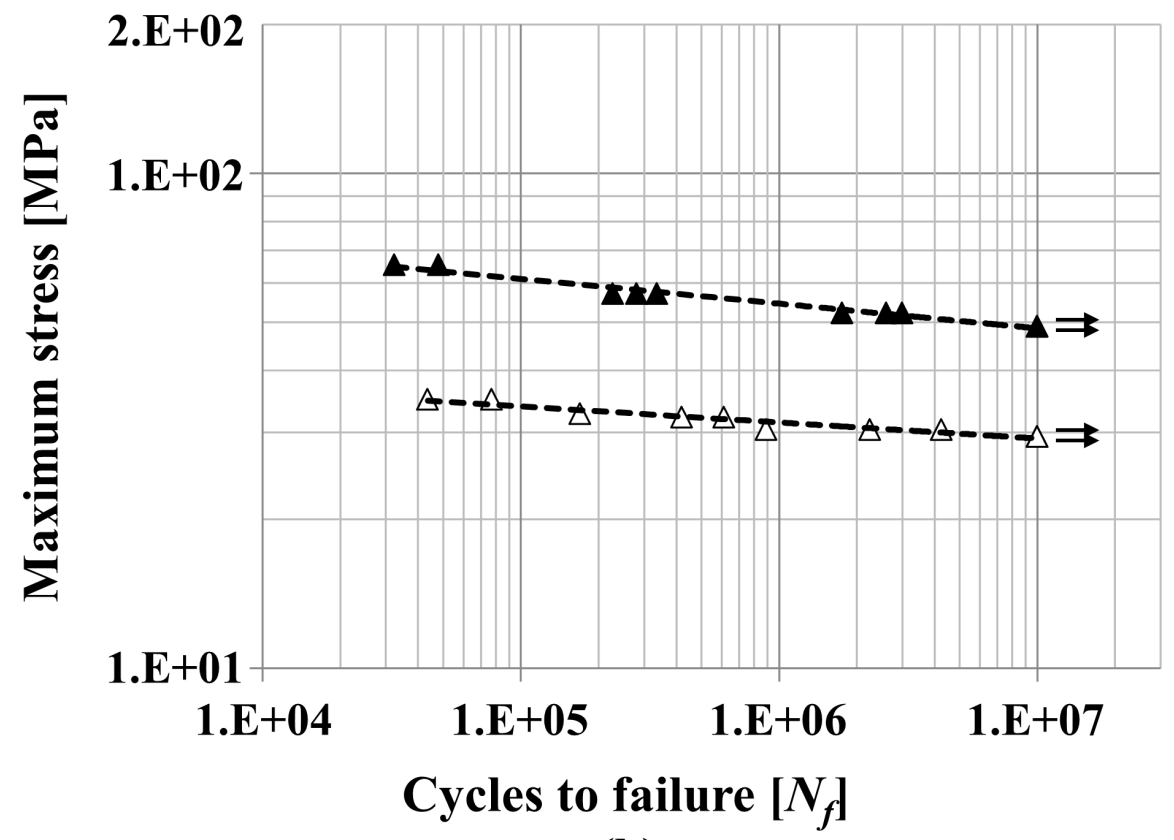

(b) 


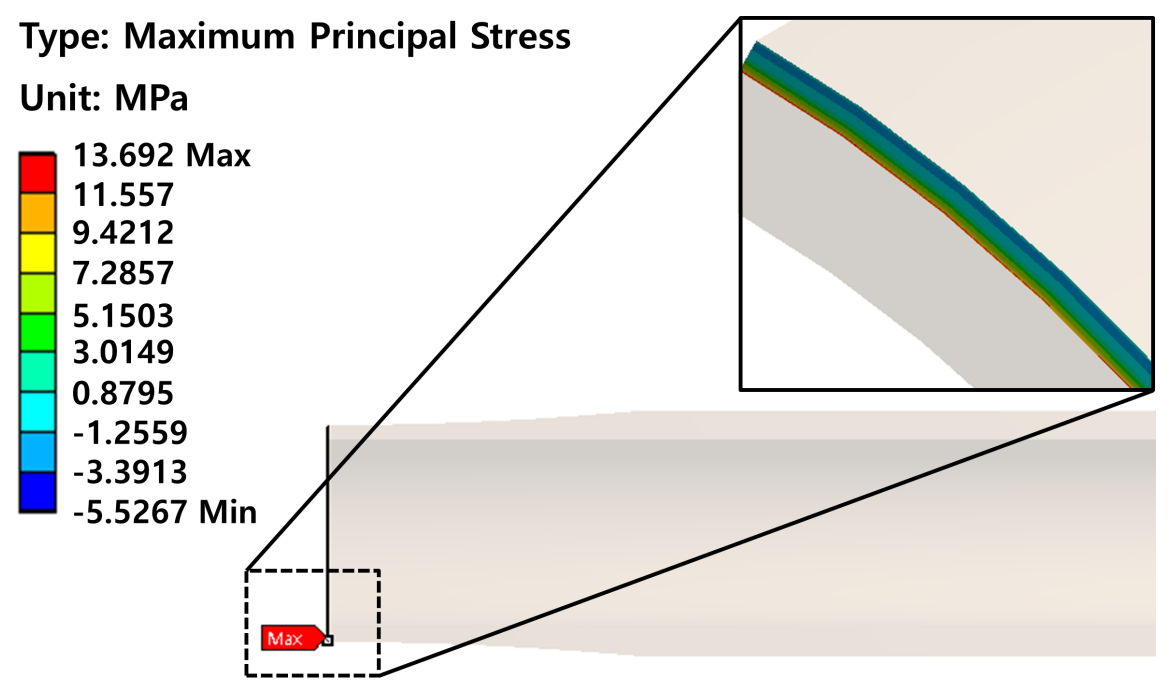

